\title{
Structural and Spectroscopic Characterization of
}

\author{
Two \\ New \\ Layered \\ Uranyl(VI) \\ $p$ -
}

xylenediphosphonate Compounds Synthesized via

\section{Ionothermal Method}

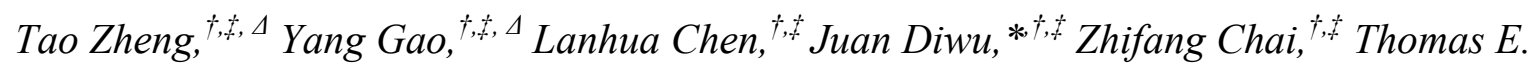

Albrecht-Schmitt, ${ }^{\S}$ Shuao Wang* ${ }^{+}$, t

${ }^{\dagger}$ School for Radiological and Interdisciplinary Sciences (RAD-X), Soochow University, Jiangsu

215123, China

Collaborative Innovation Center of Radiation Medicine of Jiangsu Higher Education Institutions, Jiangsu 215123, China

${ }^{\S}$ Department of Chemistry and Biochemistry, Florida State University, 95 Chieftain Way, Tallahassee, Florida 32306, United States

${ }^{\Delta}$ These authors contributed equally to this work

\section{ABSTRACT.}


Two new uranyl phosphonates were synthesized by using $p$-xylenediphosphonic acid $\left(\mathbf{p m b H}_{4}\right)$ to react with uranyl salts in Emim or BMMim ([EMim][PF 6$]=1$-ethyl-3methylimidazolium hexafluorophosphate; [BMMim]Cl=1-butyl-2,3-dimethylimidazolium chloride) at elevated temperature, namely $[\mathrm{EMim}]\left[\mathrm{UO}_{2}\left(\mathbf{p m b H}_{2}\right)_{0.5}\left(\mathbf{p m b H}_{2}\right)_{0.5}(\mathrm{ox})_{0.5}\right](\mathbf{1})$ and [BMMim $]_{2}\left[\left(\mathrm{UO}_{2}\right)_{2}\left(\mathbf{p m b H}_{2}\right)(\mathbf{p m b})\right]$ (2). Both compounds adopt two dimensional structures, consisting of an anionic layer of uranyl phosphonate, with cations filled in the interlayer spaces. The spectroscopic properties of the compounds were studied extensively using UV-Vis absorption, temperature dependent fluorescence, Raman and IR spectroscopies. The UV-Vis absorption spectrum contains typical peaks of uranyl complexes at around $320 \mathrm{~nm}$ and $420 \mathrm{~nm}$, which are originated from the charge transfer transitions from $O 2 p$ orbitals to the $U 5 f / 6 d$ orbitals. Both compounds adopt five strong emission peaks, whose intensities increase with the decrease of temperature, as observed in the temperature dependent fluorescence spectra. In Raman and IR spectra, the peaks corresponding to the stretch of $\mathrm{C}-\mathrm{H} / \mathrm{O}-\mathrm{H}, \mathrm{P}-\mathrm{O} / \mathrm{P}=\mathrm{O}$, and $\mathrm{O} \equiv \mathrm{U} \equiv \mathrm{O}$ bonds could all be located and assigned.

\section{Introduction}

During the last several decades, the field of metal phosphonates has received increasing attention owing to their potential applications in catalysis [1,2], proton conductivity [3-5], gas absorption and separation [6-8], magnetism [8-11], and optics [12]. The crystal chemistry of actinide phosphonates is an important subfield of metal phosphonates, where major attention was paid to uranium [13-19] and thorium [20-22], with only a few neptunium [22-24], plutonium [2528], and americium [28] complexes. Layered structure is always observed in uranyl phosphonates, due to the nature of equatorial coordination sites (from four to six) of the uranyl 
ion, leading the structure to $2 \mathrm{D}$ topologies $[19,29-34]$. There are only several phosphonate ligands that were extensively studied to yield 1D, 2D and 3D structures, namely $p$ xylenediphosphonic acid $\left(\mathbf{p m b H}_{4}\right)$ [35, 36], 2-phosphonoacetic acid $\left(\mathrm{paH}_{3}\right)$ [32, 33, 37], 4phosphonobenzoic acid (4- $\left.\mathrm{cppH}_{3}\right)$ [38], (1-hydroxyethane-1,1-diyl)bis(phosphonic acid) (iopH 4$)$ $[19,39]$, and 1,4-phenylenebis(phosphonic acid) $\left(1,4-\mathrm{bdpH}_{4}\right)[13,34,40,41]$. Both $\mathrm{paH}_{3}$ and 4$\mathrm{cppH}_{3}$ are bi-functional ligands, where the carboxylate and the phosphonate group are connected via a carbon skeleton, while $\operatorname{iopH}_{4}$ and 1,4-bdpH 4 are bi-phosphonate ligands. Among all the compounds obtained from those two bi-functional ligands, $\mathrm{UO}_{2}(\mathrm{paH})\left(\mathrm{H}_{2} \mathrm{O}\right) \cdot 2 \mathrm{H}_{2} \mathrm{O}$ [37] and $\mathrm{Cs}_{2}\left[\left(\mathrm{UO}_{2}\right)_{2}\left(4-\mathrm{cppH}_{2}\right)_{3}(4-\mathrm{cppH}) \mathrm{F}\right]$ [38] are 1D structure compound with a protonated carboxylate group. As the carboxylate group was deprotonated, 2D [21, 32, 42] and 3D [38, 43-46] compounds were obtained by linking the uranyl carboxylate chains together using the phosphonate groups. For iopH $\mathrm{H}_{4}$ and 1,4-bdpH 4 bi-phosphonate ligands, 1D chain and nanotube structures were also found in $(\mathrm{Hbpi})\left[\left(\mathrm{UO}_{2}\right)\left(\mathrm{H}_{2} \mathrm{O}\right)(\mathrm{iopH})\right] \cdot \mathrm{H}_{2} \mathrm{O} \quad[19], \quad$ (teah) $\left[\left(\mathrm{UO}_{2}\right)(4-\right.$ bdpH $\left.\left.\mathrm{H}_{2.5}\right)_{2}\left(\mathrm{H}_{2} \mathrm{O}\right)\right]$ [40], and $\mathrm{Cs}_{3.62} \mathrm{H}_{0.38}\left[\left(\mathrm{UO}_{2}\right)_{4}\left(4-\mathrm{bdpH}_{2}\right)_{3}(4-\mathrm{bdp}) \mathrm{F}_{2}\right]$ [13], with the last one showing a special 1D-nanotube structure. 2D and 3D structures were obtained by the phosphonate groups playing the same role of linking uranyl chains together as described above for $\mathrm{paH}_{3}$ and 4-cppH .

On the other hand, as a new family of 'green' reaction media, ionic liquids (ILs) have received considerable attention owing to their advantages compared to water and organic solvents, such as low vapor pressure at high temperature, nonflammability, nonexplosiveness, and wide 'electrochemical window' $[47,48]$. ILs are defined as salts that are in the liquid state at arbitrary temperature, such as $100{ }^{\circ} \mathrm{C}$ and could be utilized as a multi-functional media for the syntheses of new actinide phosphonate compounds, as reported by Parker et al [49, 50]. However, 
continued research is still required to further understand the role ILs play in the structure formation and arrangements.

In this work, $\mathbf{p m b H}_{4}$ ligands were used for constructing new uranyl phosphonate structures via ionothermal methods to explore the structural chemistry of uranyl phosphonate in the ILs. These ILs act as both solvents and structural templates, thus greatly affecting the structure topology of the resulting compounds. Herein, the synthesis and structures of two new uranyl phosphonates, namely $\quad[\mathrm{EMim}]\left[\mathrm{UO}_{2}\left(\mathbf{p m b H}_{2}\right)_{0.5}\left(\mathbf{p m b H}_{2}\right)_{0.5}(\mathrm{ox})_{0.5}\right] \quad$ (1) and $\left.[\mathrm{BMMim}]_{2}\left[\left(\mathrm{UO}_{2}\right)_{2}(\mathbf{p m b H})_{2}\right)(\mathbf{p m b})\right]$ (2), are reported and their physical properties are comprehensively characterized. ( $\mathbf{p m b H}_{4}=p$-xylenediphosphonic acid); $\left[\mathrm{EMim}_{[}\left[\mathrm{PF}_{6}\right]=1\right.$-ethyl-3methylimidazolium hexafluorophosphate; [BMMim]Cl=1-butyl-2,3-dimethylimidazolium chloride) (Scheme 1).
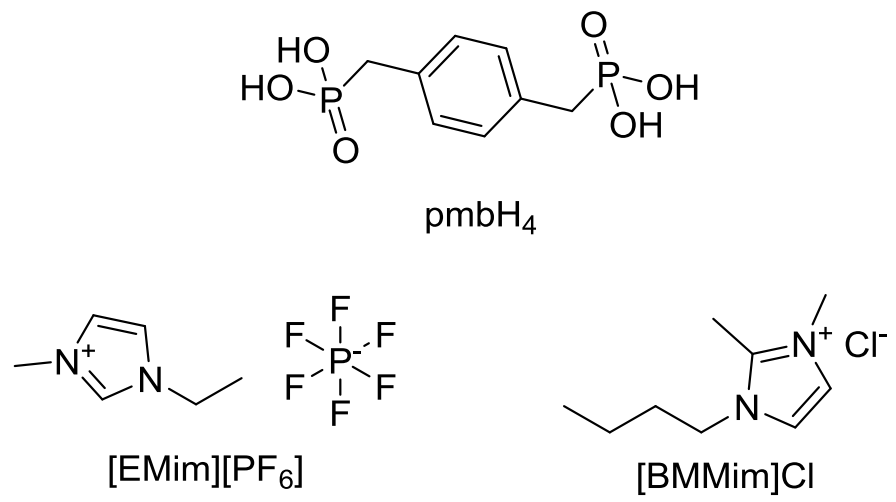

Scheme 1. Phosphonate ligands and ionic liquids used in this work.

\section{Experimental Section}


Caution! While all uranium compounds used in these studies contained depleted uranium, standard precautions were performed for handling radioactive materials, and all studies were conducted in a laboratory dedicated to research on actinide elements.

Materials and Methods. $p$-xylenediphosphonic acid $\left(\mathbf{p m b H}_{4}\right)$ was synthesized by similar procedure reported in the literature[36, 51], $\mathrm{UO}_{2}\left(\mathrm{NO}_{3}\right)_{2} \cdot 6 \mathrm{H}_{2} \mathrm{O}$, solution of $\mathrm{HF}(40 \%)$, and ionic liquids were used as received. The samples were separated manually using an optical microscope for physical property measurements.

Syntheses of Compound $[\mathrm{EMim}]\left[\mathrm{UO}_{2}\left(\mathbf{p m b H}_{2}\right)_{0.5}\left(\mathbf{p m b H}_{2}\right)_{0.5}(\mathrm{ox})_{0.5}\right]$ (1): A mixture of $\mathrm{UO}_{2}(\mathrm{AcO})_{2} \cdot 6 \mathrm{H}_{2} \mathrm{O} \quad(0.05 \mathrm{mmol}, \quad 0.0218 \mathrm{~g}), \quad \mathbf{p m b H}_{4}(0.1 \mathrm{mmol}, \quad 0.0267 \mathrm{~g}), \quad$ 1-ethyl-3methylimidazolium hexafluorophosphate $(0.5 \mathrm{~mL})$, and 1 drop of $\mathrm{HF}(40 \%)$, was placed in a 15 $\mathrm{mL}$ Teflon-lined stainless steel vessel and heated at $120^{\circ} \mathrm{C}$ for $120 \mathrm{~h}$, and then cooled to room temperature. Yellow block crystals were collected with impurities. IR $\left(\mathrm{KBr}, \mathrm{cm}^{-1}\right)$ : 3427(vs,b), 3151(w), 2926(w), 2856(w), 1657(vs), 1568(m), 1514(s), 1462(w), 1425(w), 1406(s), 1260(m), 1198(m), 1170(vs), 1113(vs), 1095(vs), 1072(vs), 1053(vs), 1041(vs), 1022(vs), 994(vs), 951(vs), 918(vs), 845(s), 819(m), 799(m), 791(s), 756(m), 739(m), 717(w), 702(w), 650(m), 623(m), 571(vs), 561(vs), 533(w), 488(m), 465(w), 432(m). Raman ( $\left.\mathrm{cm}^{-1}\right)$ : 1608(w), 1480(w), 1420(w), 1335(w), 1248(w), 1187(w), 1095(w), 1017(w), 949(w), 831(s), 774(w), 638(w), 596(w), 510(w), 310(w), 205(w), 70(s). Fluorescence peak: 500.7(s), 522.3(vs), 546.2(s), 571.5(m), 600.0(w), 631.0(vw).

Syntheses of Compound $[\mathrm{BMMim}]_{2}\left[\left(\mathrm{UO}_{2}\right)_{2}\left(\mathbf{p m b H}_{2}\right)(\mathbf{p m b})\right](\mathbf{2})$ : Under the same temperature condition as compound 1, a mixture of $\mathrm{UO}_{2}\left(\mathrm{NO}_{3}\right)_{2} \cdot 6 \mathrm{H}_{2} \mathrm{O}(0.05 \mathrm{mmol}, 0.0253 \mathrm{~g}), \mathbf{p m b H} \mathrm{H}_{4}(0.1$ mmol, $0.0267 \mathrm{~g}), 1$-butyl-2,3-dimethylimidazolium chloride $(1 \mathrm{mmol}, 0.1891 \mathrm{~g})$, and 1 drop of HF (40 \%) was placed in a $15 \mathrm{~mL}$ Teflon-lined stainless steel vessel to react. Yellow needle-like 
crystals were obtained. IR (KBr, cm $\left.{ }^{-1}\right)$ : 3441(vs,b), 3175(w), 3137(s), 2955(s), 2933(w), 2870(s), 1729(w), 1630(s), 1587(s), 1540(s), 1512(m), 1467(vs), 1420(s), 1382(s), 1337(w), 1296(w), 1251(vs), 1236(vs), 1194(s), 1132(vs), 1117(w), 1100(m), 1053(w), 910(vs), 769(s), 754(m), 742(s), 721(w), 669(m), 633(m),475(w), 445(w), 435(w). Raman $\left(\mathrm{cm}^{-1}\right):$ 1507(w), 1440(w), 1335(w), 1115(w), 1051(w), 960(w), 903(w), 824(s), 751(w), 718(w), 675(w), 627(w), 605(w), 343(w), 307(w), 256(s), 202(s), 95(s). Fluorescence peak: 500.7(s), 522.3(vs), 545.4(s), 570.7(m), 598.2(w), 615.7(vw), 627.9(vw).

Crystallographic Studies. Crystals of compounds 1 and $\mathbf{2}$ were mounted on Cryoloops with paratone and then optically aligned on a single crystal X-ray diffractometer (Bruker D8-Venture) equipped with a digital camera. The diffraction data were collected at room temperature, by using a Turbo X-ray Source (Mo-K $\alpha$ radiation, $\lambda=0.71073 \AA$ ) adopting the direct-drive rotating anode technique and a CMOS detector. The structures of all compounds were solved by the direct method and refined on $\mathrm{F}^{2}$ by full-matrix least-squares methods using SHELXTL ${ }^{[52]}$ and all the non-hydrogen atoms were refined anisotropically. The protons are difficult to locate since their electron densities are too low, thus all hydrogen atoms were put in calculated positions, which might cause level B alert of " D-H no Acceptor" for compound 2. The hydrogen atoms that were theoretically bonded to disordered carbon or nitrogen atoms in ILs were not added.

UV-Vis, Fluorescence, Raman and Infrared Spectra. UV-Vis spectroscopy data were obtained from single crystals of compound $\mathbf{1}$ and $\mathbf{2}$ from 200 to $800 \mathrm{~nm}$, with crystals placed on quartz slides, using the Craic Technologies microspectrophotometer in transmission mode. Under the irradiation of light with $365 \mathrm{~nm}$ wavelength, fluorescence spectra was recorded at 293, $273,223,173,123$, and $93 \mathrm{~K}$, respectively. Raman spectra were collected in the range of 
50 2000 $\mathrm{cm}^{-1}$ with crystals placed on quartz slides without oil. The room temperature infrared spectra were measured on a Bruker VERTX 70 FT-IR instrument.

\section{Results and Discussion}

Structure Descriptions.

Table 1. Crystallographic Data and Refinement Details for $\mathbf{1}$ and 2.

\begin{tabular}{|c|c|c|}
\hline & 1 & 2 \\
\hline Formula & $\mathrm{C}_{15} \mathrm{H}_{21} \mathrm{~N}_{2} \mathrm{O}_{10} \mathrm{P}_{2} \mathrm{U}$ & $\mathrm{C}_{34} \mathrm{H}_{34} \mathrm{~N}_{4} \mathrm{O}_{16} \mathrm{P}_{4} \mathrm{U}_{2}$ \\
\hline M & 689.31 & 1354.59 \\
\hline Crystal system & Triclinic & Triclinic \\
\hline Space group & $P \overline{1}$ & $P \overline{1}$ \\
\hline $\mathrm{a} / \AA$ & $10.154(1)$ & $9.376(1)$ \\
\hline $\mathrm{b} / \AA$ & $10.465(2)$ & $11.292(1)$ \\
\hline $\mathrm{c} / \AA$ & $11.626(2)$ & $22.411(2)$ \\
\hline$\alpha / \circ$ & $84.877(3)$ & $75.529(2)$ \\
\hline$\beta / \circ$ & $76.789(3)$ & $81.513(2)$ \\
\hline$\gamma / \circ$ & $68.203(3)$ & $83.506(2)$ \\
\hline $\mathrm{V} / \AA^{3}$ & $1116.7(3)$ & $2265.2(3)$ \\
\hline $\mathrm{Z}$ & 2 & 2 \\
\hline$\rho_{\text {calcd }} / \mathrm{g} \mathrm{cm}^{-3}$ & 2.05 & 1.986 \\
\hline $\mathrm{F}(000)$ & 654 & 1276 \\
\hline$\mu(\mathrm{Mo}-\mathrm{K} \alpha) / \mathrm{mm}^{-1}$ & 7.463 & 7.35 \\
\hline GooF on $\mathrm{F}^{2}$ & 1.031 & 1.129 \\
\hline
\end{tabular}




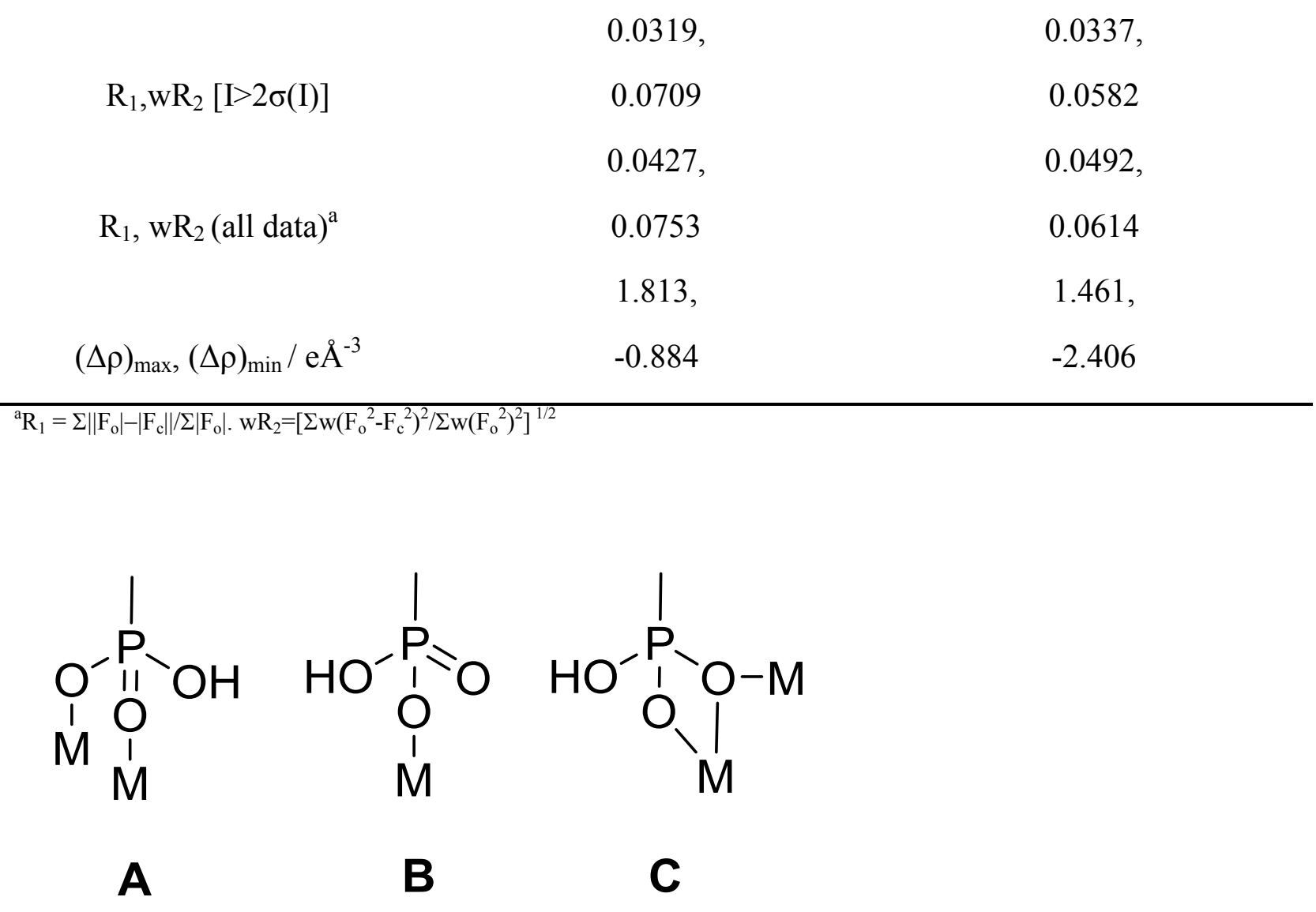

Scheme 2. Coordination modes of the phosphonate group.

\section{Crystal structure of $[\mathrm{EMim}]\left[\mathrm{UO}_{2}\left(\mathrm{pmbH}_{2}\right)_{0.5}\left(\mathrm{pmbH}_{2}\right)_{0.5}(\mathrm{ox})_{0.5}\right](1)$}

Compound 1 crystallizes in the triclinic space group $P \overline{1}$ (Table 1). The asymmetric unit contains one $\mathrm{UO}_{2}{ }^{2+}$ cation, two half pmb, half oxalate ligand, and one 1-ethyl-3methylimidazolium anion (Fig. 1). $\mathrm{UO}_{2}{ }^{2+}$ cation adopts a pentagonal bipyramid coordination geometry, forming a $\mathrm{UO}_{7}$ unit. The five oxygen atoms located on the equatorial plane are $\mathrm{O} 1$, $\mathrm{O} 4$, and $\mathrm{O} 2 \mathrm{~A}$ provided by three pmb ligands, as well as $\mathrm{O} 9$ and $\mathrm{O} 10 \mathrm{~B}$ from the oxalate ligand (symmetric codes for 1 : A: $-x+2,-y+1,-z+1 ; B:-x+1,-y+2,-z+1)$. The origin of the unexpected oxalate ligand could be the acetate ion from the uranyl acetate used as the starting material, since such in situ formation of oxalate from the carboxylate groups have been reported previously[53]. 
The oxalate ligand formed in situ by using acetate anion during the reaction [53]. The pmb ligands, with coordination modes $\mathbf{A}$ and $\mathbf{B}$ (Scheme 2), act as the bridging units. The two $\mathrm{UO}_{7}$ units that are chelated by oxalate ligands form a pseudo dimer, which is then linked by $\mathrm{CPO}_{3}$ groups to give a chain (Fig. 2). The chains are further connected by the pmb ligands to extend along the $c$ axis. 1-ethyl-3-methylimidazolium cations are filled between layers. The $\mathrm{U} \equiv \mathrm{O}$ and $\mathrm{U}-\mathrm{O}$ bond lengths are in the ranges of $1.760(4)-1.763(4) \AA$ and $2.314(4)-2.466(4) \AA$, respectively (Table 2), which are in good agreement with published bond lengths.[16, 29, 40] The bond distances of P1-O3 and P2-O6 are 1.560(4) and 1.564(4) $\AA$, respectively, indicating that $\mathrm{O} 3$ and $\mathrm{O} 6$ are protonated.

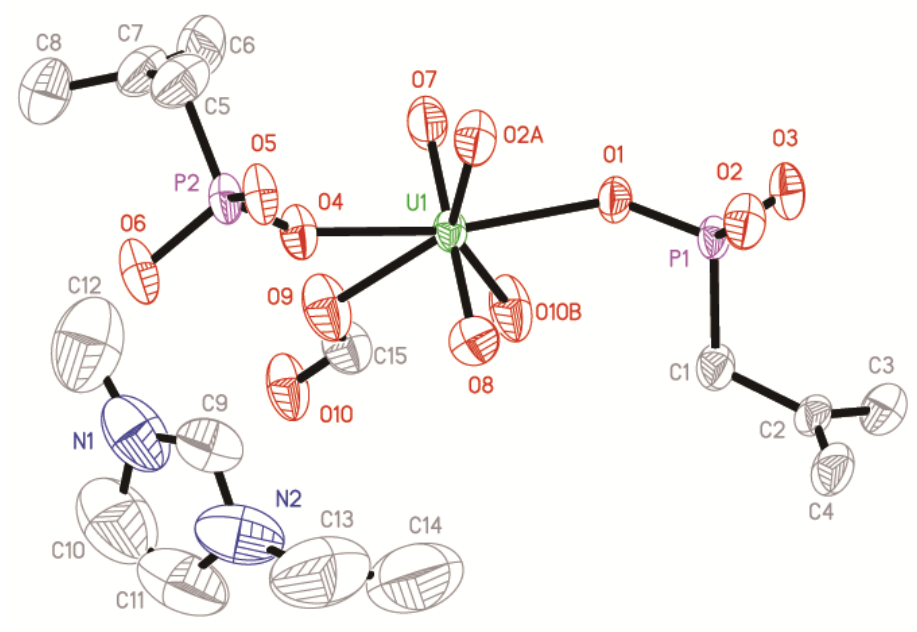

Fig. 1. ORTEP pattern of compound 1 with atomic labeling scheme at 50\% probability, and all hydrogen atoms are omitted for clarity. 

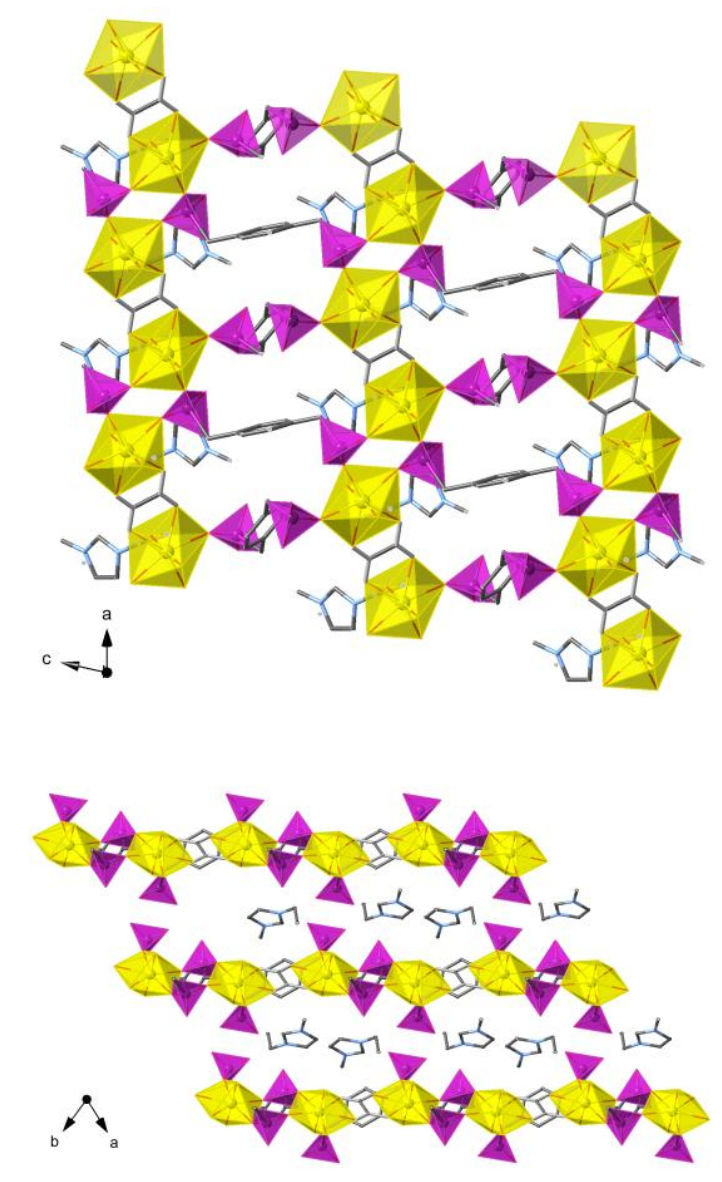

Fig. 2. Layer structure viewed along $b$ and $c$ axis (up) and (down) of compound $\mathbf{1} \cdot \mathrm{UO}_{7}$ is represented as yellow pentagonal bipyramid and $\mathrm{CPO}_{3}$ is shown as purple tetrahedron.

Table 2. Selected Bond Distances $(\AA)$ for compound 1.

\begin{tabular}{llll}
\hline $\mathrm{U} 1 \equiv \mathrm{O} 8$ & $1.760(4)$ & $\mathrm{P} 1-\mathrm{O} 2$ & $1.504(4)$ \\
$\mathrm{U} 1 \equiv \mathrm{O} 7$ & $1.763(4)$ & $\mathrm{P} 1-\mathrm{O} 1$ & $1.506(4)$ \\
$\mathrm{U} 1-\mathrm{O} 2 \mathrm{~A}$ & $2.314(4)$ & $\mathrm{P} 1-\mathrm{O} 3$ & $1.560(4)$ \\
$\mathrm{U} 1-\mathrm{O} 1$ & $2.318(4)$ & $\mathrm{P} 2-\mathrm{O} 4$ & $1.489(4)$ \\
$\mathrm{U} 1-\mathrm{O} 4$ & $2.334(4)$ & $\mathrm{P} 2-\mathrm{O} 5$ & $1.513(4)$ \\
$\mathrm{U} 1-\mathrm{O} 9$ & $2.454(4)$ & $\mathrm{P} 2-\mathrm{O} 6$ & $1.564(4)$ \\
$\mathrm{U} 1-\mathrm{O} 10 \mathrm{~B}$ & $2.466(4)$ & &
\end{tabular}

Symmetric codes for 1 : A: $-\mathrm{x}+2,-\mathrm{y}+1,-\mathrm{z}+1 ; \mathrm{B}:-\mathrm{x}+1,-\mathrm{y}+2,-\mathrm{z}+1$. 


\section{Crystal structure of $[\mathrm{BMMim}]_{2}\left[\left(\mathrm{UO}_{2}\right)_{2}\left(\mathrm{pmbH}_{2}\right)(\mathrm{pmb})\right](2)$}

Similar with $\mathbf{1}$, compound 2 also crystallizes in the triclinic space group $P \overline{1}$ (Table 1 ), but the $c$ axis is almost doubled. So the asymmetric unit contains two $\mathrm{UO}_{2}{ }^{2+}$ cations, four half pmb ligands, and two 1-butyl-2,3-dimethylimidazolium cations (Fig. 3). Both $\mathrm{UO}_{2}{ }^{2+}$ cations adopt pentagonal bipyramid coordination geometry, with five oxygen atoms located in the equatorial plane $(\mathrm{O} 2, \mathrm{O} 3, \mathrm{O} 4, \mathrm{O} 7$ and $\mathrm{O} 11 \mathrm{~A}$ for $\mathrm{U} 1$ and $\mathrm{O} 5, \mathrm{O} 9, \mathrm{O} 11, \mathrm{O} 12$ and $\mathrm{O} 3 \mathrm{~B}$ for $\mathrm{U} 2$, symmetric codes for 2: A: $\mathrm{x}+1, \mathrm{y}, \mathrm{z} ; \mathrm{B}: \mathrm{x}-1, \mathrm{y}, \mathrm{z}$.). The $\mathbf{p m b}$ ligands with coordination modes of $\mathbf{A}$ and $\mathbf{C}$ (Scheme 2) act as both chelating and bridging ligands. A dimer of U1 and U2 is obtained by edge-sharing $\mu_{3}-\mathrm{O} 3$ and $\mu_{3}-\mathrm{O} 11$. The uranium dimers are bridged by the $\mathrm{CPO}_{3}$ groups to extend along the $a$ axis to give a chain, which are further connected by the organic moiety of pmb ligand to form the layered topology. The charge of the anionic layer is compensated with 1butyl-2,3-dimethylimidazolium cations filled in the space. The $\mathrm{U} \equiv \mathrm{O}$ and $\mathrm{U}-\mathrm{O}$ bond lengths are in the range of 1.775(3)-1.778(3) $\AA$ and 2.298(3)-2.553(3) $\AA$, respectively (Table 3). Although the bond distance of P1-O3 is 1.560(3) A, the Bond Valence Sum (BVS) calculation result of O3 is 2.075 v.u., indicating full deprotonation of the phosphonate, since it is a $\mu_{3}-\mathrm{O}$ bonded to one phosphor atom and two uranyl centers. $[54,55]$ The remaining atoms $\mathrm{P}$ and $\mathrm{O}$, in the phosphonate groups, whose bond distances are in the range of 1.540(4)-1.550(4) A, should be protonated as indicated by the BVS calculation. 


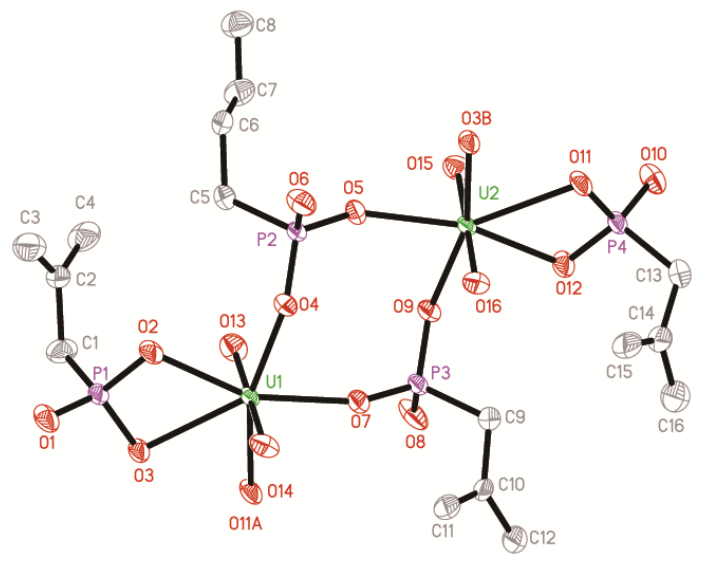

Fig. 3. Asymmetric building unit of compound 2 with atomic labeling scheme at $50 \%$ probability, with all hydrogen atoms and two 1-butyl-2,3-dimethylimidazolium cations omitted for clarity.

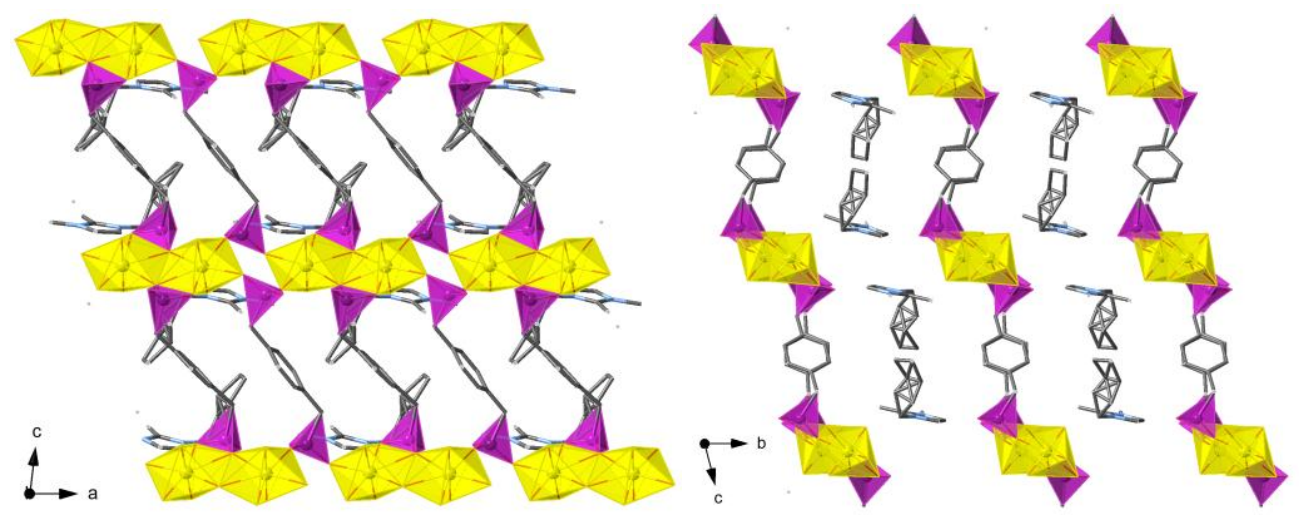

Fig. 4. Layer structure viewed along $b$ and $a$ axis (left and right) of compound 2. $\mathrm{UO}_{7}$ is represented as yellow pentagonal bipyramid, $\mathrm{CPO}_{3}$ is shown as purple tetrahedron.

Table 3. Selected Bond Distances $(\AA)$ for compound 2.

\begin{tabular}{llll}
\hline $\mathrm{U} 1 \equiv \mathrm{O} 14$ & $1.776(3)$ & $\mathrm{U} 2-\mathrm{O} 11$ & $2.553(3)$ \\
$\mathrm{U} 1 \equiv \mathrm{O} 13$ & $1.777(3)$ & $\mathrm{P} 1-\mathrm{O} 1$ & $1.503(4)$ \\
$\mathrm{U} 1-\mathrm{O} 7$ & $2.298(3)$ & $\mathrm{P} 1-\mathrm{O} 2$ & $1.528(3)$ \\
$\mathrm{U} 1-\mathrm{O} 4$ & $2.323(3)$ & $\mathrm{P} 1-\mathrm{O} 3$ & $1.560(3)$ \\
$\mathrm{U} 1-\mathrm{O} 2$ & $2.390(3)$ & $\mathrm{P} 2-\mathrm{O} 5$ & $1.509(3)$ \\
$\mathrm{U} 1-\mathrm{O} 11 \mathrm{~A}$ & $2.390(3)$ & $\mathrm{P} 2-\mathrm{O} 4$ & $1.516(3)$ \\
\hline
\end{tabular}




\begin{tabular}{llll}
\hline $\mathrm{U} 1-\mathrm{O} 3$ & $2.535(3)$ & $\mathrm{P} 2-\mathrm{O} 6$ & $1.550(4)$ \\
$\mathrm{U} 2-\mathrm{O} 16$ & $1.775(3)$ & $\mathrm{P} 3-\mathrm{O} 7$ & $1.512(4)$ \\
$\mathrm{U} 2-\mathrm{O} 15$ & $1.778(3)$ & $\mathrm{P} 3-\mathrm{O} 9$ & $1.524(3)$ \\
$\mathrm{U} 2-09$ & $2.316(3)$ & $\mathrm{P} 3-\mathrm{O} 8$ & $1.540(4)$ \\
$\mathrm{U} 2-\mathrm{O} 5$ & $2.326(3)$ & $\mathrm{P} 4-\mathrm{O} 10$ & $1.511(4)$ \\
$\mathrm{U} 2-\mathrm{O} 3 \mathrm{~B}$ & $2.356(3)$ & $\mathrm{P} 4-\mathrm{O} 12$ & $1.520(3)$ \\
$\mathrm{U} 2-\mathrm{O} 12$ & $2.394(3)$ & $\mathrm{P} 4-\mathrm{O} 11$ & $1.544(4)$ \\
\hline
\end{tabular}

Symmetric codes for 2: A: $\mathrm{x}+1, \mathrm{y}, \mathrm{z} ; \mathrm{B}: \mathrm{x}-1, \mathrm{y}, \mathrm{z}$.

We have previously investigated the coordination chemistry of uranyl with $\mathrm{pmbH}_{4}$ ligand under hydrothermal conditions [36], where three new uranyl phosphonates were obtained with different dimensionalities by tuning the organic templates and $\mathrm{pH}$. Detailed structural comparison between uranyl pmb compounds synthesized hydrothermally and ionothermally reveals that they differ in the local coordination environment of uranium, structure topology, as well as the overall dimension of the structure. Firstly, the local coordination environment of uranium ions reported in this study both show pentagonal bipyramid geometry with five oxygen atoms all coming from the $\mathrm{CPO}_{3}$ moieties, whereas in the hydrothermal compounds, the coordination number of uranyl equatorial plane is four or five. In addition, water molecule was able to involve in bonding in [TPA] $\left[\mathrm{UO}_{2}\left(\mathrm{pmbH}_{3}\right)\left(\mathrm{pmbH}_{2}\right) \mathrm{H}_{2} \mathrm{O}\right] \cdot 2 \mathrm{H}_{2} \mathrm{O}$ [36]. Obviously, ionothermal method is an effective way to eliminate water coordination, although it is present in the reaction systems. Secondly, by altering the $\mathrm{pH}$, which greatly effects the protonation of phosphonate ligands, chains, layers, and framework structures could all be obtained in the hydrothermal systems. In the ionothermal reactions, however, both products can only adopt layered topology. Further comparison between compound $\mathbf{2}$ and $\mathrm{UO}_{2}\left(\mathrm{pmbH}_{2}\right) \cdot 2 \mathrm{H}_{2} \mathrm{O}$ shows that although the $\mathrm{CPO}_{3}$ groups chelate and bridge the uranium centers in the same manner, the 
existence of cations from ILs results in a stretch of the chain topology and expand the interlayer space [36]. Despite losing $\mathrm{pH}$ as an adjustable parameter in ionothermal reactions to alter the structure of the products, owing to the variation of the cations and anions in the ionic liquid family, it is interesting and a logically next step to systematically explore the structural chemistry of uranium in the ionic liquids at the elevated temperature, which may yield uranium based functional materials and new separation methodology based on selective crystallization under ionothermal conditions.

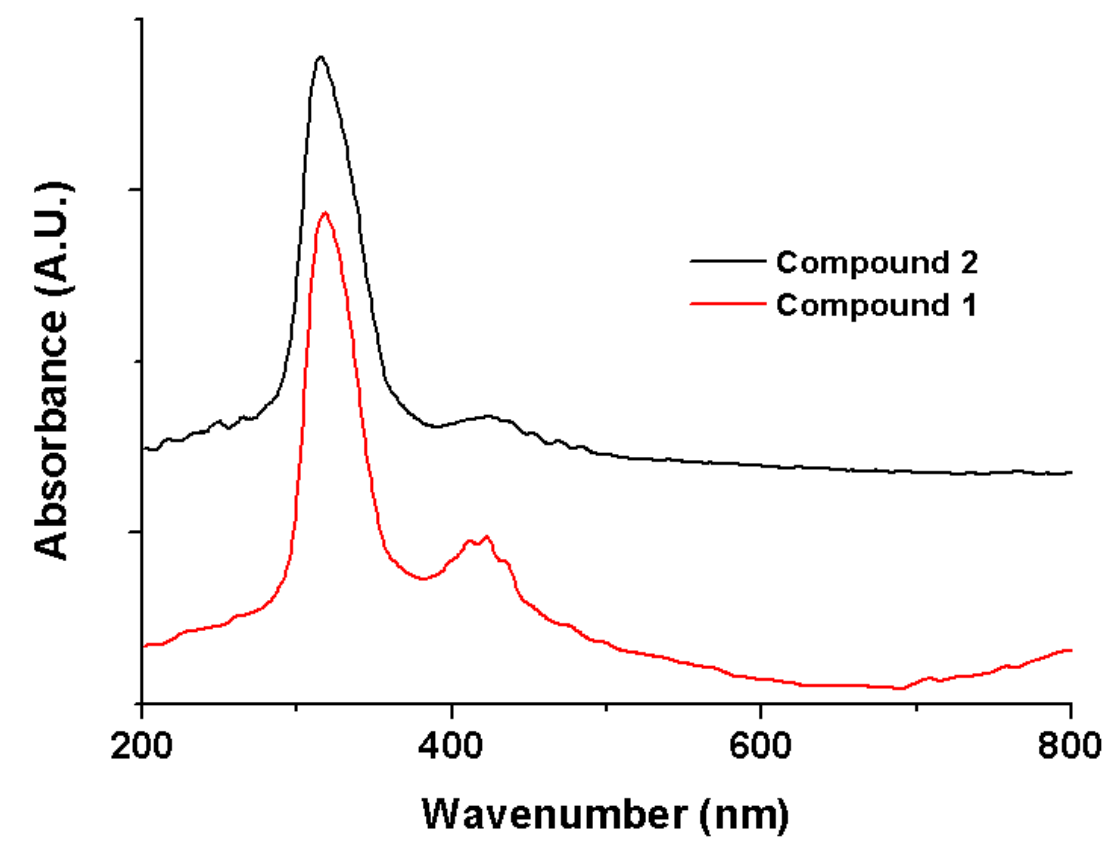

Fig. 5. UV-Vis spectra of compounds $\mathbf{1}$ and $\mathbf{2}$. The spectra are elevated for clarity.

\section{Spectroscopic Properties.}

The UV-Vis absorption spectra of both compounds are shown in Fig. 5. The peaks near 320 $\mathrm{nm}$ (317.5 for compound $\mathbf{1}$, and 315.2 for $\mathbf{2}$,) and peaks around $420 \mathrm{~nm}$ can be assigned to be 
generated from the charge transfer from $\mathrm{O} 2 \mathrm{p}$ orbitals to the $\mathrm{U} 5 \mathrm{f} / 6 \mathrm{~d}$ orbitals, coupled with vibrations [20, 56].
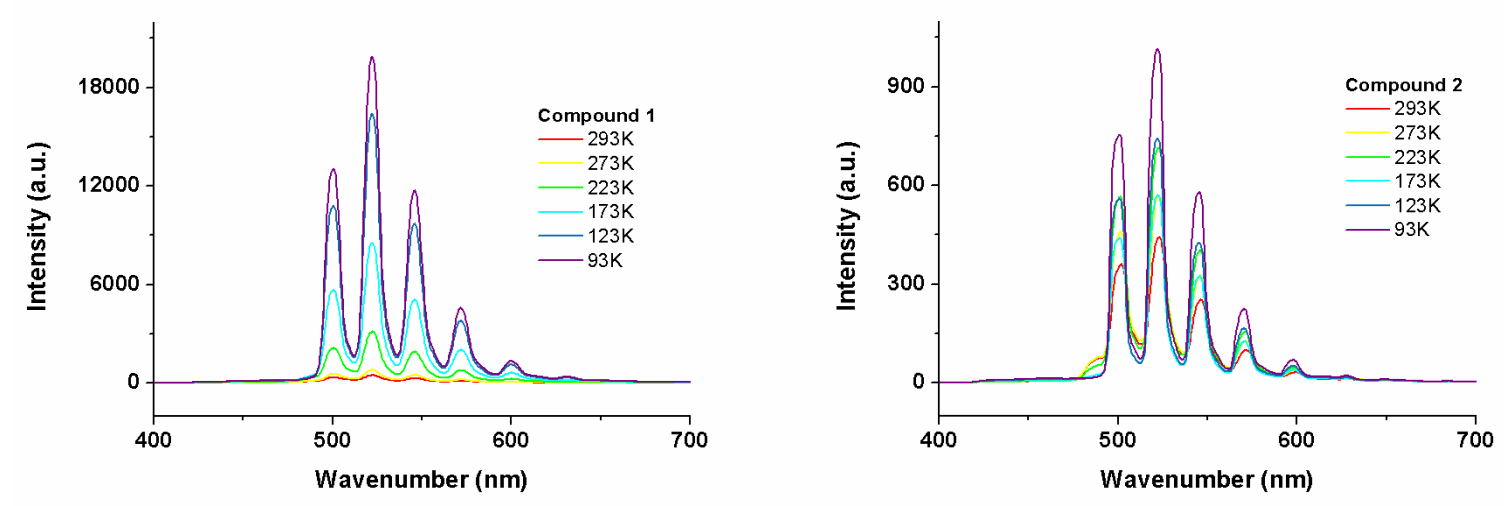

Fig. 6. Fluorescence spectra at different temperature of compound $\mathbf{1}$ and 2.

The charge-transfer based emission of yellow-green light in the range of $500 \sim 600 \mathrm{~nm}$ is mainly due to LUMO-HOMO electronic transitions coupled with symmetric and antisymmetric stretch vibrations of the nearly linear $\mathrm{O} \equiv \mathrm{U} \equiv \mathrm{O}$ unit (Fig. 6) $[20,34,57,58]$. Fingerprint peaks are typically observed in uranyl compounds and the intensities of fluorescence spectra of compound $\mathbf{1}$ and $\mathbf{2}$ increase with the decrease of temperature, which is quite similar to spectroscopic properties reported in other work [36, 38, 40, 59]. Such a phenomenon is generally originated from the promotion of non-radiative emission of phonon at elevated temperature. 

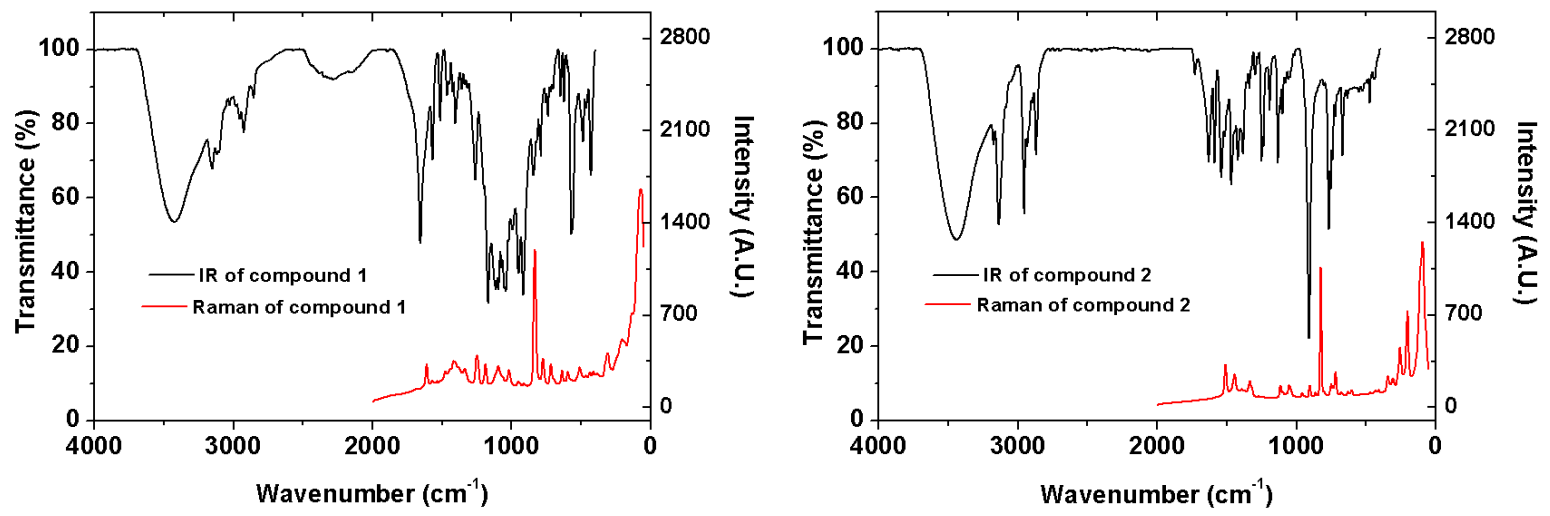

Fig. 7. IR and Raman spectra of compounds 1 and 2.

Infrared (IR) and Raman spectra were also recorded for both compounds (Fig. 7). For IR spectra, the peaks between 3800 and $2500 \mathrm{~cm}^{-1}$ are mainly assigned to the stretch of C-H (R-C$\mathrm{H})$ and/or O-H (P-O-H). The peaks appearing in the range of $1640-1390 \mathrm{~cm}^{-1}$ are corresponding to the stretch of benzene ring and/or cations from ILs. The typical anti-symmetric and symmetric stretch peaks of $\mathrm{P}=\mathrm{O}$ and $\mathrm{P}-\mathrm{O}$ in the range of 1245 to $950 \mathrm{~cm}^{-1}$ are observed in both compounds $[16,60]$. The anti-symmetric and symmetric stretch peaks of $\mathrm{O} \equiv \mathrm{U} \equiv \mathrm{O}$ are active (the intensity of peak is strong) in IR and Raman, respectively, and are assigned accordingly (918 and $831 \mathrm{~cm}^{-1}$ for $1 ; 910$ and $824 \mathrm{~cm}^{-1}$ for 2 ).

\section{Conclusions}

In summary, two new uranyl phosphonate compounds were obtained by ionothermal method. Both adopt anionic layered topology. In compound 1, oxalate ligand was transformed from acetate in the uranyl starting material, which helped to construct 1D uranyl-phosphonate chain. In contrast, a dimer of $\mathrm{UO}_{7}$ was shown in compound 2, which was then extended to $1 \mathrm{D}$ chain via phosphonate linkage. The layer was obtained by the connection of pmb ligand in both 
compounds, with cations of ILs filled between the layers. Both compounds present characteristic uranyl absorption peaks from $300 \mathrm{~nm}$ to $800 \mathrm{~nm}$ region, as well as fingerprint five peak emission in fluorescence spectra. The temperature dependent fluorescence spectroscopy further illustrate that the intensity of the emission is in negative correlation with temperature. In our future work, investigating the structural topology and dimension in relation to the ILs conformation will be one of the major concerns, with the potential applications in the areas of uranium based functional materials and uranium separation based on selective crystallization under ionothermal conditions.

\section{Acknowledgments}

We are grateful for funding supported by National Science Foundation of China (91326112, 21422704, 21471107, 81402628), the Science Foundation of Jiangsu Province (BK20140007, BK20140303), a Project Funded by the Priority Academic Program Development of Jiangsu Higher Education Institutions (PAPD), and "Young Thousand Talented Program" in China. Support for TEA-S was provided by the Chemical Sciences, Geosciences, and Biosciences Division, Office of Basic Energy Sciences, Office of Science, Heavy Elements Chemistry Program, U.S. Department of Energy, under Grant DE-FG0213ER16414.

Supporting Information Available: X-ray crystallographic files in cif format, for compound $\mathbf{1}$ and $\mathbf{2}$ are supplied in supporting information. This material is available free of charge via the Internet at www.journals.elsevier.com.

\section{Corresponding Author}

Prof. Dr. Shuao Wang (shuaowang@suda.edu.cn);

Prof. Dr. Juan Diwu (diwujuan@suda.edu.cn); 


\section{REFERENCES}

[1] Z. Wang, J.M. Heising, A. Clearfield, J. Am. Chem. Soc., 125 (2003) 10375.

[2] L. Ma, C. Abney, W. Lin, Chem. Soc. Rev., 38 (2009) 1248.

[3] S.-S. Bao, K. Otsubo, J.M. Taylor, Z. Jiang, L.-M. Zheng, H. Kitagawa, J. Am. Chem. Soc., 136 (2014) 9292.

[4] X. Liang, F. Zhang, W. Feng, X. Zou, C. Zhao, H. Na, C. Liu, F. Sun, G. Zhu, Chem. Sci., 4 (2013) 983.

[5] J.M. Taylor, R.K. Mah, I.L. Moudrakovski, C.I. Ratcliffe, R. Vaidhyanathan, G.K.H.

Shimizu, J. Am. Chem. Soc., 132 (2010) 14055.

[6] S.S. Iremonger, J. Liang, R. Vaidhyanathan, G.K.H. Shimizu, Chem. Commun., 47 (2011) 4430.

[7] S.S. Iremonger, J. Liang, R. Vaidhyanathan, I. Martens, G.K.H. Shimizu, T.D. Daff, M.Z. Aghaji, S. Yeganegi, T.K. Woo, J. Am. Chem. Soc., 133 (2011) 20048.

[8] T. Zheng, J.M. Clemente-Juan, J. Ma, L. Dong, S.-S. Bao, J. Huang, E. Coronado, L.-M. Zheng, Chem-eur. J., 19 (2013) 16394.

[9] M. Ren, S.-S. Bao, N. Hoshino, T. Akutagawa, B. Wang, Y.-C. Ding, S. Wei, L.-M. Zheng, Chem-eur. J., 19 (2013) 9619.

[10] Y.-Z. Zheng, M. Evangelisti, F. Tuna, R.E.P. Winpenny, J. Am. Chem. Soc., 134 (2011) 1057.

[11] T.-T. Wang, M. Ren, S.-S. Bao, B. Liu, L. Pi, Z.-S. Cai, Z.-H. Zheng, Z.-L. Xu, L.-M. Zheng, Inorg. Chem., 53 (2014) 3117.

[12] D. Senthil Raja, P.-C. Lin, W.-R. Liu, J.-X. Zhan, X.-Y. Fu, C.-H. Lin, Inorg. Chem., (2015).

[13] P.O. Adelani, T.E. Albrecht-Schmitt, Angew. Chem. Int. Ed., 49 (2010) 8909.

[14] A.-G.D. Nelson, T.H. Bray, T.E. Albrecht-Schmitt, Angew. Chem. Int. Ed., 47 (2008) 6252.

[15] D.M. Poojary, D. Grohol, A. Clearfield, Angew. Chem. Int. Ed., 34 (1995) 1508.

[16] D. Grohol, A. Clearfield, J. Am. Chem. Soc., 119 (1997) 4662.

[17] J. Diwu, T.E. Albrecht-Schmitt, Chem. Commun., 48 (2012) 3827.

[18] S.-S. Bao, G.-S. Chen, Y. Wang, Y.-Z. Li, L.-M. Zheng, Q.-H. Luo, Inorg. Chem., 45 (2006) 1124. 
[19] W. Yang, H.-Y. Wu, R.-X. Wang, Q.-J. Pan, Z.-M. Sun, H. Zhang, Inorg. Chem., 51 (2012) 11458 .

[20] P.O. Adelani, T.E. Albrecht-Schmitt, J. Solid State Chem., 192 (2012) 377.

[21] P. Ramaswamy, R. Prabhu, S. Natarajan, Inorg. Chem., 49 (2010) 7927.

[22] A.-G.D. Nelson, T.H. Bray, F.A. Stanley, T.E. Albrecht-Schmitt, Inorg. Chem., 48 (2009) 4530 .

[23] J. Diwu, S. Wang, Z. Liao, P.C. Burns, T.E. Albrecht-Schmitt, Inorg. Chem., 49 (2010) 10074.

[24] T.H. Bray, A.-G.D. Nelson, G.B. Jin, R.G. Haire, T.E. Albrecht-Schmitt, Inorg. Chem., 46 (2007) 10959.

[25] J. Lin, J.N. Cross, J. Diwu, M.J. Polinski, E.M. Villa, T.E. Albrecht-Schmitt, Inorg. Chem., 51 (2012) 11949.

[26] J. Diwu, S. Wang, J.J. Good, V.H. DiStefano, T.E. Albrecht-Schmitt, Inorg. Chem., 50 (2011) 4842.

[27] J. Diwu, A.-G.D. Nelson, S. Wang, C.F. Campana, T.E. Albrecht-Schmitt, Inorg. Chem., 49 (2010) 3337.

[28] J. Diwu, D.J. Grant, S. Wang, L. Gagliardi, T.E. Albrecht-Schmitt, Inorg. Chem., 51 (2012) 6906.

[29] M.B. Doran, A.J. Norquist, D. O'Hare, Chem. Mater., 15 (2003) 1449.

[30] D.M. Poojary, D. Grohol, A. Clearfield, J. Phys. Chem. Solids, 56 (1995) 1383.

[31] H.-Y. Wu, Y.-Q. Ma, X. Zhang, H. Zhang, X.-Y. Yang, Y.-H. Li, H. Wang, S. Yao, W. Yang, Inorg. Chem. Commun., 34 (2013) 55.

[32] K.E. Knope, C.L. Cahill, Inorg. Chem., 47 (2008) 7660.

[33] A.N. Alsobrook, T.E. Albrecht-Schmitt, Inorg. Chem., 48 (2009) 11079.

[34] P.O. Adelani, T.E. Albrecht-Schmitt, Cryst. Growth Des., 11 (2011) 4227.

[35] B. Monteiro, J.A. Fernandes, C.C. Pereira, S.M. Vilela, J.P. Tome, J. Marçalo, F.A. Almeida Paz, Acta Cryst. B, 70 (2014) 28.

[36] T. Zheng, Q.-Y. Wu, Y. Gao, D. Gui, S. Qiu, L. Chen, D. Sheng, J. Diwu, W.-Q. Shi, Z. Chai, T.E. Albrecht-Schmitt, S. Wang, Inorg. Chem., 54 (2015) 3864.

[37] K.E. Knope, C.L. Cahill, Inorg. Chem. Commun., 13 (2010) 1040.

[38] P.O. Adelani, A.G. Oliver, T.E. Albrecht-Schmitt, Cryst. Growth Des., 11 (2011) 3072. 
[39] H.-Y. Wu, W. Yang, Z.-M. Sun, Cryst. Growth Des., 12 (2012) 4669.

[40] P.O. Adelani, A.G. Oliver, T.E. Albrecht-Schmitt, Cryst. Growth Des., 11 (2011) 1966.

[41] P.O. Adelani, T.E. Albrecht-Schmitt, J. Solid State Chem., 184 (2011) 2368.

[42] K.E. Knope, C.L. Cahill, Inorg. Chem., 48 (2009) 6845.

[43] A.N. Alsobrook, E.V. Alekseev, W. Depmeier, T.E. Albrecht-Schmitt, Cryst. Growth Des., 11 (2011) 2358.

[44] A.N. Alsobrook, E.V. Alekseev, W. Depmeier, T.E. Albrecht-Schmitt, J. Solid State Chem., 184 (2011) 1195.

[45] A.N. Alsobrook, B.G. Hauser, J.T. Hupp, E.V. Alekseev, W. Depmeier, T.E. AlbrechtSchmitt, Cryst. Growth Des., 11 (2011) 1385.

[46] A.N. Alsobrook, B.G. Hauser, J.T. Hupp, E.V. Alekseev, W. Depmeier, T.E. AlbrechtSchmitt, Chem. Commun., 46 (2010) 9167.

[47] K. Binnemans, Chem. Rev. (Washington, DC, U. S.), 107 (2007) 2592.

[48] R.E. Morris, Chem. Commun., (2009) 2990.

[49] T.G. Parker, J.N. Cross, M.J. Polinski, J. Lin, T.E. Albrecht-Schmitt, Cryst. Growth Des., 14 (2014) 228.

[50] E.R. Cooper, C.D. Andrews, P.S. Wheatley, P.B. Webb, P. Wormald, R.E. Morris, Nature, 430 (2004) 1012.

[51] M. Pramanik, M. Nandi, H. Uyama, A. Bhaumik, Green Chem., 14 (2012) 2273.

[52] G.M. Sheldrick, SHELXTL, Siemens Analytical X-ray Instruments, Inc: Madison, WI, 2001.

[53] S. Dalai, M. Bera, A. Rana, D.S. Chowdhuri, E. Zangrando, Inorg. Chim. Acta, 363 (2010) 3407.

[54] N.E. Brese, M. Okeeffe, Acta Crystallogr. B, 47 (1991) 192.

[55] P.C. Burns, R.C. Ewing, F.C. Hawthorne, Can. Mineral., 35 (1997) 1551.

[56] R.G. Denning, J. Phys. Chem. A, 111 (2007) 4125.

[57] J. Su, K. Zhang, W.H.E. Schwarz, J. Li, Inorg. Chem., 50 (2011) 2082.

[58] P.O. Adelani, T.E. Albrecht-Schmitt, Cryst. Growth Des., 12 (2012) 5800.

[59] Q. Zhu, R. Shang, S. Chen, C. Liu, Z. Wang, S. Gao, Inorg. Chem., 53 (2014) 8708.

[60] D. Grohol, M.A. Subramanian, D.M. Poojary, A. Clearfield, Inorg. Chem., 35 (1996) 5264. 
